\title{
A auditoria de processo como suporte à melhoria contínua: estudo de caso em uma montadora de automóveis
}

\author{
Douglas da Costa Ferreira, M.Sc. \\ UNIFAE - FAE Business School \\ douglas.ferreira@fae.edu
}

Andréia Marize Rodrigues, Dra.

FCAV/UNESP - Departamento de Economia Rural

andreiamarize@fcav.unesp.br

Marcelo Giroto Rebelato, Dr.

FCAV/UNESP - Departamento de Economia Rural

mgiroto@fcav.unesp.br

Marcelo Gechele Cleto, Ph.D.

Universidade Federal do Paraná - Departamento de Engenharia Mecânica $\underline{\text { mgcleto@ufpr.br }}$

Esse artigo apresenta a auditoria de processo como ferramenta de apoio à melhoria contínua em processos de manufatura. Para tanto, foi realizado um estudo de caso no processo de Montagem de Partes Móveis na área de Armação de Carrocerias em uma montadora de automóveis que realiza auditorias de processo conforme a norma VDA 6.3 (Verband der Automobilindustrie 6.3). Através de análise documental, entrevistas e observações in loco, foi possível avaliar, num período de um ano e meio, a evolução do desempenho do processo estudado e as principais ações de melhoria relacionadas com algumas não-conformidades observadas em auditorias de processo. $\mathrm{O}$ estudo ressalta as singularidades da auditoria de processo em contraponto às auditorias de produto e de sistema da qualidade e conclui que a auditoria de processo é efetiva como ferramenta de suporte à melhoria contínua.

Palavras-chave: auditoria de processo; norma vda 6.3; indústria automobilística

This article presents the processes audit as a tool to support the continuous improvement in manufacturing processes. For that, it was realized a case study at the spears parts assembly line into a automobile factory body shop that perform processes audit by the VDA 6.3 standard (Verband der Automobilindustrie 6.3). Thru the documentation analysis, interviews and in loco observations, it was possible evaluate, in a period of one year and a half, the evolution of the studied process performance and the principal improvement actions related to some non-conformities observed in processes audit. The survey highlights the processes audit singularities against to the product audit and quality system audit and remarks the effectiveness of the processes audit as a tool to support the continuous improvement.

Keywords: process audit; VDA 6.3 standard; automotive industry

\section{Introdução}

A procura por melhorias em produtos e serviços tem sido cada vez mais intensa nos diversos ramos industriais e em especial na indústria automobilística que, via de regra, se encontra em um constante processo de desenvolvimento de novos métodos e práticas gerenciais e que rapidamente são seguidos 
pelos demais seguimentos industriais (WOMACK et al., 1992). Essa busca por melhorias tem apresentado especial impacto sobre os processos de fabricação e seus métodos de controle.

A melhoria no processo produtivo não é, entretanto, uma tarefa fácil. A busca pela melhoria da qualidade em um processo de fabricação remete a várias possibilidades em termos de métodos, ferramentas e conceitos de gestão da qualidade. Entre esses, deve-se destacar o papel da auditoria de processo, que se apresenta como uma ferramenta efetiva para a prevenção e correção de falhas em processos produtivos, fornecendo elementos para sua melhoria contínua.

Apesar das auditorias de processos se mostrarem eficazes na deteç̧ão, prevenção e eliminação de nãoconformidades no processo produtivo, elas são pouco empregadas. Sua utilização é verificada sobretudo nas empresas automobilísticas de origem alemã (BMW, Mercedes-Benz e Volkswagen). A despeito de sua baixa utilização e considerando a sua utilidade na melhoria da qualidade, o objetivo desse artigo é apresentar a auditoria de processo como ferramenta de suporte à melhoria contínua a partir de um estudo de caso realizado na montadora Volkswagen do Brasil LTDA., na planta de São José dos Pinhais/PR (BUC - Business Unit Curitiba). Neste estudo de caso foram contemplados a aplicação e os resultados obtidos com as auditorias de processo guiadas pela norma VDA 6.3 (Verband der Automobilindustrie 6.3).

Para tanto, este artigo encontra-se descrito em sete tópicos, a contar com esta introdução. A definição de auditoria de processo encontra-se no próximo tópico. Complementando a revisão bibliográfica realizada, os tópicos três e quatro abordam, respectivamente, a relação entre auditoria de processo e melhoria contínua e faz algumas considerações sobre a auditoria de processo de acordo com a norma VDA 6.3.

O tópico cinco descreve a metodologia utilizada para a realização deste trabalho e o sexto tópico trata da descrição dos dados coletados na pesquisa de campo. Finalmente, no tópico 7 apresentam-se as conclusões, relacionando a auditoria de processo com a melhoria contínua.

\section{Conceituação de auditoria de processos}

Conforme Mills (1994), auditoria consiste na realização de uma avaliação reconhecida oficialmente e sistematizada pelos interessados, com a finalidade de assegurar que o sistema, programa, produto, serviço e processo aplicáveis perfaçam todas as características, critérios e parâmetros exigidos. Há vários tipos de auditoria: auditoria contábil, auditoria corporativa, auditoria ambiental, auditorias de fornecedores, auditorias de saúde e segurança ocupacional, auditorias de qualidade, etc., cada uma com seus parâmetros de exigência e interessados específicos. As auditorias de qualidade são aquelas em que principal objetivo é verificar a conformidade de um sistema ${ }^{1}$ em relação ao que foi determinado, sejam em normas, procedimentos, legislações, entre outros.

A condução de auditorias da qualidade pode ser realizada de duas formas: auditoria externa, realizada por uma entidade externa à organização e auditoria interna, conduzida por membros da própria organização. Em Campos (1992) e em VDA 6.3 (1998), as auditorias de qualidade são divididas em três tipos:

a) Auditoria de Produto: procura identificar se o produto produzido atende às características previamente estabelecidas (especificação);

b) Auditoria do Sistema da Qualidade: esta auditoria é realizada baseando-se em uma norma de gestão, como a ISO 9001:2000 ou a QS 9000, por exemplo. A empresa que se submete a este tipo de auditoria procura sua certificação no atendimento aos requisitos de uma norma de Gestão da Qualidade. Esta auditoria consiste em verificar a aplicação das recomendações da norma e a conformidade da execução do trabalho com relação ao seu procedimento;

\footnotetext{
${ }^{1}$ Entende-se por sistema um agrupamento de atividades com um determinado fim, por exemplo, o sistema de recebimento de matéria-prima em uma empresa (SLACK et al, 2002).
} 
c) Auditoria de Processo: esse tipo de auditoria procura identificar as falhas no processo, através de análise de parâmetros operacionais e do conhecimento técnico dos auditores.

Dados seus diferentes objetivos, cada uma destas auditorias da qualidade possui características, abrangência e efeitos diferentes umas das outras. As auditorias de produto, por exemplo, avaliam a conformidade de produtos e, em caso da detecção de falhas, podem levar à tomada de ações corretivas, de certo modo impedindo a reincidência de uma mesma não-conformidade.

Contudo, as auditorias de produto, assim como as inspeções, têm um caráter puramente corretivo em relação à qualidade, pois não possuem a propriedade de acompanhar tendências ou padrões de comportamento na realização dos procedimentos dos processos de produção para prever futuras falhas. Devido à baixa amostragem e ao fato de não "bloquear" os lotes auditados, as não-conformidades detectadas na auditoria de produto normalmente já atingiram o cliente (FERNANDES, 2005).

Quanto às auditorias de sistemas, estas possuem um foco mais global, não se atentando para detalhes e particulares dos processos. Nestas auditorias, o auditor deve ser profundo conhecedor da norma $\mathrm{e}$ possuir grande habilidade na condução e execução de auditorias. Seu foco principal consiste em verificar a aplicação da norma e a conformidade dos processos em relação aos requisitos desta norma, não sendo necessários conhecimentos específicos sobre características técnicas dos processos auditados.

Desta maneira, detalhes técnicos e específicos do processo normalmente fogem da especialidade do auditor de sistemas. Além disso, as auditorias de sistemas que recebem mais atenção são as auditorias externas, e estas são tipicamente auditorias de conformidades, sendo sua ênfase na verificação do cumprimento dos padrões especificados e não em encontrar uma melhor maneira de se realizar um dado trabalho (BAFNA, 1997; WYNNIE \& MANNERS, 2001).

Por estas lacunas encontradas nas auditorias de produto e de sistemas, destaque deve ser dado às auditorias de processo. O princípio básico de uma auditoria de processo é alocar um auditor com conhecimentos específicos sobre o processo a ser auditado para verificar a realização das atividades produtivas e as atividades de apoio ao processo produtivo.

As auditorias de processo normalmente são auditorias internas e focam na identificação de nãoconformidades em relação às especificações do processo, procedimentos de trabalho, organização e limpeza, treinamento, logística e em relação a diversas outras exigências relacionadas ao processo produtivo. Focando nas falhas do processo é possível evitar que estas levem a uma futura falha no produto, sendo a auditoria de processo uma atividade com alto foco preventivo (FERNANDES, 2005), isto não excluindo o seu caráter também corretivo. A figura 1 diferencia o foco de atuação das auditorias de sistema, processo e de produto.

Diferentemente das auditorias da qualidade baseadas nas normas de gestão da qualidade - ISO 9001:2000, VDA 6.1 ou QS 9000, por exemplo - na execução de auditorias de processo o auditor deve conhecer os detalhes técnicos das atividades relacionadas ao processo a ser auditado, tais como parâmetros, especificações, normas técnicas e índices de classe mundial. Esses dados técnicos, somados aos itens da norma de referência, auxiliam o auditor na elaboração de um check-list para acompanhamento da auditoria.

Como exemplo, durante uma operação de soldagem, em uma auditoria de sistema, o auditor verifica a quantidade de pontos de solda exigidos pelo desenho do produto e se o soldador está executando os pontos exigidos neste desenho. Em uma auditoria de processo o auditor poderá verificar se o ângulo do eletrodo em relação à chapa é adequado. É de seu conhecimento que este ângulo influencia o tamanho do ponto de solda, e que pontos de solda pequenos irão trazer menor resistência mecânica ao conjunto soldado e eventual comprometimento da qualidade da peça.

Olhando a mesma questão sob a ótica da auditoria de sistema, o tamanho do "botão" do ponto de solda poderia também ser verificado. No entanto, essa verificação somente ocorreria se o auditor 
encontrasse um documento especificando o tamanho do ponto de solda, ou seja, se houvessem requisitos de análise de medição do ponto de solda. Na execução de auditorias de processo o auditor não precisa encontrar um documento "de referência" ou contar com a "habilidade de inspetores de processo". Como é conhecedor da tarefa a ser auditada, o auditor de processo pode contar com sua própria habilidade para fazer tais verificações.

Desta maneira, mesmo não havendo uma evidência objetiva na documentação para as análises, o auditor de processo deve valer-se de sua experiência e de seus conhecimentos para identificar nãoconformidades. Não é incomum um processo avaliado por uma auditoria de sistema, em que foram identificadas uma ou duas não-conformidades, que durante a realização de uma auditoria de processo se identifiquem dez a vinte não-conformidades.

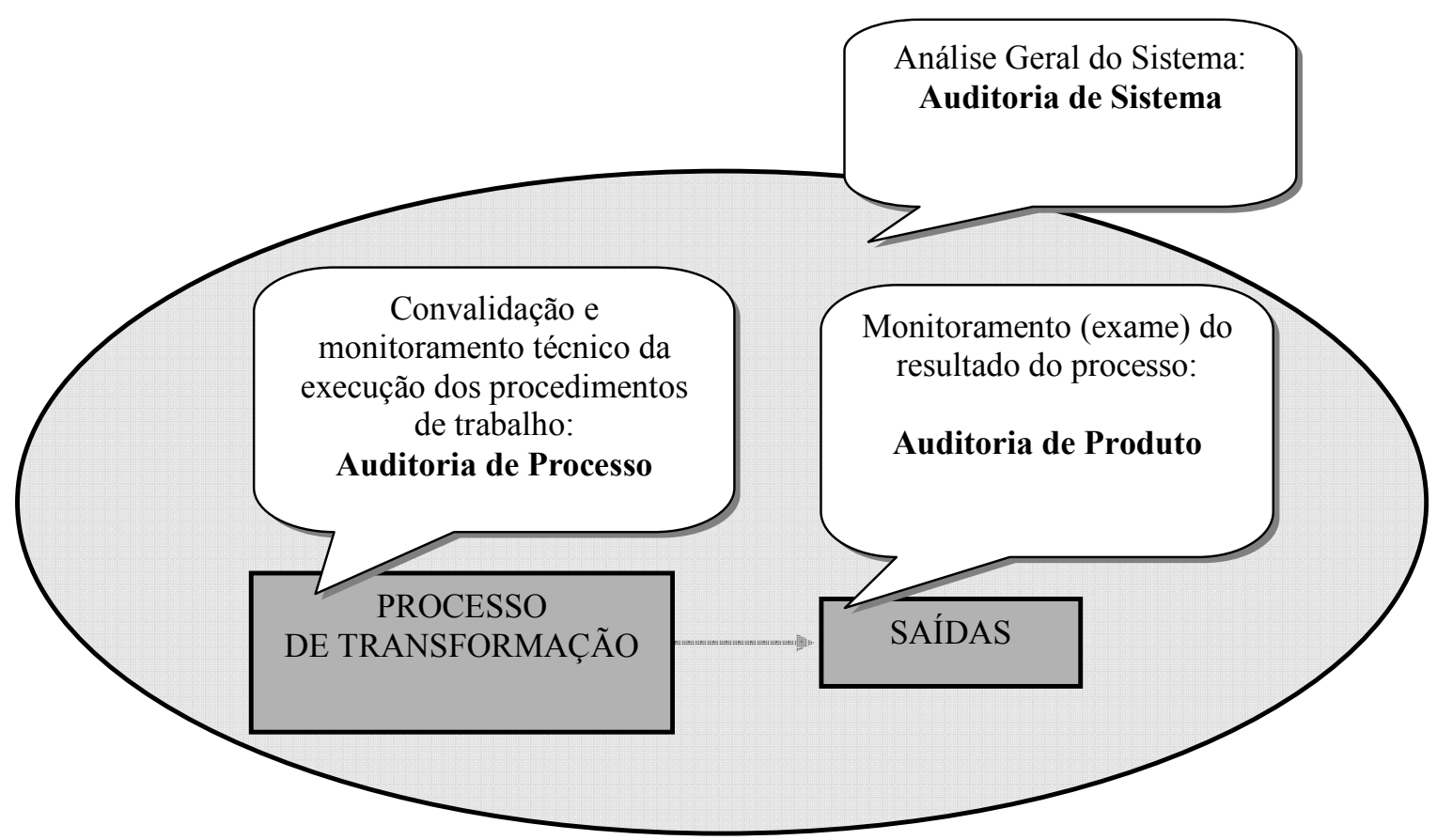

Figura 1 - Foco de atuação das auditorias de produto e de processo

Para a condução de auditorias de processo deve-se seguir o mesmo formato geral e estrutura da condução das outras auditorias, a saber:

a) Preparação: formulação e utilização de check-list adequado para cada processo a ser auditado;

b) Condução: a auditoria deve ser conduzida por apenas um auditor e somente em caso de processos muito complexos é interessante a presença de dois auditores;

c) Relatório: deve ser simples e relatar apenas fatos relevantes, tais como a finalidade da auditoria, data e hora de realização; o nome do auditor; o processo examinado; e as conclusões da auditoria;

d) Follow up: este consiste no aspecto mais crítico da auditoria. Caso discrepâncias sejam encontradas, passos devem ser seguidos para corrigi-las. Isto pode ser feito corrigindo o desempenho dos processos ou mudando, quando necessário, as instruções (BAFNA, 1997; WINNIE \& MANNERS, 2001).

Os mesmos autores recomendam que a etapa relativa ao follow up seja realizada pelos responsáveis pelo processo, que devem executar as ações de melhorias sugeridas, caso necessárias. Além disso, é importante que os resultados das ações tanto corretivas quanto preventivas sejam examinados quando o processo for auditado novamente. 
Com relação à determinação de quais processos serão os permanentemente avaliados pelas auditorias de processo, Bafna (1997) e VDA 6.3 (1998) defendem que sejam utilizados critérios específicos da empresa, tais como a importância relativa do processo com relação às operações da empresa, por exemplo.

O primeiro autor a alertar para o importante papel desempenhado pela condução de auditorias voltadas especificamente para os processos de manufatura foi Skinner (1969), apresentando a auditoria em processos como uma ferramenta importante para estabelecer uma série de políticas de manufatura quando do desenho do sistema de produção. De lá para cá, porém, a auditoria de processo permaneceu relevada a um segundo plano, já que a norma de gestão da qualidade mais amplamente utilizada, a ISO 9001:2000, não prevê a auditoria de processo em seu escopo.

De acordo com Bafna (1997), esta pouca atenção dada às auditoria de processo deve-se também a obstáculos que as empresas podem vir a encontrar para sua implementação, entre os quais o autor destaca a existência de um mito presente entre os funcionários de que esta auditoria é menos importante que as demais auditorias da qualidade. Além disso, os funcionários vêem a auditoria de processos como um instrumento de espionagem do seu trabalho e por isso a temem ou acham que seu resultado pode significar carga extra de trabalho.

Para dirimir estes preconceitos, o autor sugere que as metas a serem perseguidas pelas auditorias de processos sejam amplamente divulgadas pela organização, atestando sua utilidade, sendo reforçado que esta é uma ferramenta que pode levar ao aprimoramento contínuo de seu trabalho, e não um meio de verificação de erros para que a gerência possa punir os envolvidos.

Ressalta-se que, embora a auditoria de processo muitas vezes se apresente na literatura como o "parente pobre" na família das auditorias, ela leva ao exame e à avaliação de um processo em profundidade (BAFNA, 1997).

\section{Os impactos da auditoria de processos na melhoria contínua}

O conceito de melhoria contínua surgiu nas práticas adotadas pelas empresas japonesas após a Segunda Guerra Mundial. Também denominada de Kaizen, esta filosofia prega a busca contínua de formas para melhorar as operações de uma empresa. Este conceito traz a perspectiva de atuar nas causas de um problema potencial antes mesmo de se notar os seus possíveis efeitos (RITZMAN e KRAJEWSKI, 2004). A melhoria contínua encontra-se embasada na crença de que todos os aspectos de uma operação podem ser continuamente melhorados, partindo do princípio que os envolvidos diretamente em uma operação se constituem nos principais atores capazes de identificar alterações que devem ser realizadas (IMAI, 1997).

De acordo com Hamel e Prahalad (1995), a busca da competitividade necessita, entre outros fatores, da melhoria contínua de processos. Desta maneira, Cole (2001) destaca o aprendizado e o caráter investigativo em processos como as principais características da melhoria contínua, sendo que sua essência está na habilidade de solucionar problemas de maneira efetiva. A obtenção de resultados que revelem a melhoria contínua pressupõe a resolução de problemas da empresa mediante métodos de análise que facilitem o encontro da sua causa-raiz.

Apesar do importante papel certamente desempenhado pelas auditorias de produto e de sistemas, as melhorias incrementais nos processos individuais que podem ser proporcionadas a partir das nãoconformidades observadas por intermédio das auditorias de processo podem conduzir de maneira mais eficaz à melhoria contínua (BAFNA, 1997). As auditorias de produto, por exemplo, são executadas após a realização de tarefas produtivas, ou seja, possui foco meramente corretivo. Já as auditorias de sistema, apesar de apresentarem focos tanto corretivo quanto preventivo, possuem sua abrangência e freqüência de realização relativamente baixas quando comparadas às auditorias de processo. 
Neste contexto insere-se a auditoria de processo como um instrumento para melhoria contínua, atuando com dois enfoques:

a) Foco corretivo: Procedimentos de trabalho que não são seguidos ou que não garantam o resultado (produto) esperado - quer seja por dificuldade de realização da instrução de trabalho ou pela falta de clareza na mesma - podem ser alterados (Figura 2).

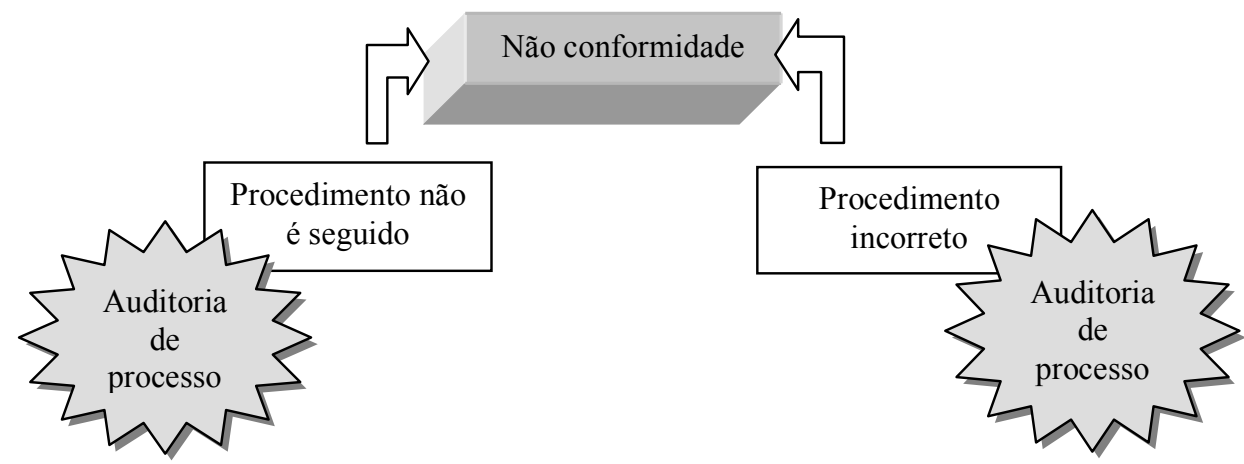

Figura 2 - Alcance das auditorias de sistema e de processo em uma atuação corretiva

b) Foco preventivo: Um procedimento de trabalho sempre pode ser melhorado. A atuação do auditor de processo no sentido de melhorar o procedimento reflete diretamente na prevenção da ocorrência de potenciais não-conformidades (Figura 3).

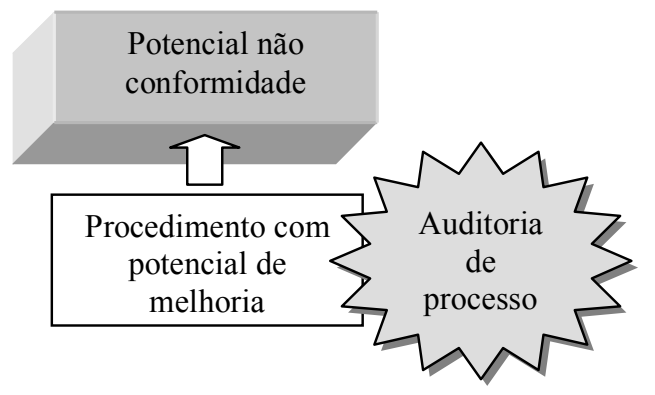

Figura 3 - Alcance das auditorias de processo em uma atuação preventiva

Entretanto, para o alcance de patamares desejáveis de melhoria contínua, deve-se buscar agregar valor às auditorias e, para isso, deve-se tornar úteis as informações de seus resultados. Para conduzir a um processo de melhoria contínua, a auditoria de processo não deve ser limitada à avaliação de conformidades, mas ir além, permitindo discussões entre auditor e auditado sobre melhorias potenciais na operação em questão. Isto é possível nas auditorias de processos internas já que auditores e auditados pertencem à mesma empresa e, portanto, é de se esperar que possuam interesses comuns (WINNIE e MANNERS, 2001).

A auditoria de processos pode ser realizada de acordo com os critérios estabelecidos pela empresa ou, a exemplo dos sistemas da qualidade, pode valer-se das recomendações de uma norma específica para auxiliar na sua execução.

A empresa em que foram coletados e analisados os dados utilizados neste trabalho vale-se dos preceitos da norma VDA 6.3 para a condução e análise de suas auditorias de processo. Desta maneira, o tópico a seguir traz uma explanação de sua estrutura. 


\section{A auditoria de processo segundo a norma VDA 6.3}

Pelo fato da norma ISO 9000 ser considerada, pelas montadoras de automóveis, insuficiente como padrão normativo para a qualidade, referenciais normativos próprios foram desenvolvidos, tal como demonstrado pela Figura 4.

\begin{tabular}{|c|c|c|}
\hline MONTADORA & PAÍS DE ORIGEM & NORMA DE SISTEMA DE QUALIDADE EXIGIDA \\
\hline $\begin{array}{l}\text { Chrysler } \\
\text { Ford } \\
\text { General Motors }\end{array}$ & Estados Unidos & $\begin{array}{l}\text { QS } 9000 \\
\text { (Quality System 9000) }\end{array}$ \\
\hline Fiat & Itália & $\begin{array}{l}\text { AVQS } \\
\text { (ANFIA Valutazione Sistemi Qualità) }\end{array}$ \\
\hline $\begin{array}{l}\text { Citroën } \\
\text { Peugeot } \\
\text { Renault } \\
\end{array}$ & França & $\begin{array}{l}\text { EAQF } \\
\text { (Evaluation Aptitude Qualité Fournisseur) }\end{array}$ \\
\hline $\begin{array}{l}\text { BMW } \\
\text { Mercedes-Benz } \\
\text { Volkswagen }\end{array}$ & Alemanha & $\begin{array}{l}\text { VDA } 6 \\
\text { (Verband der Automobilindustrie) }\end{array}$ \\
\hline
\end{tabular}

Figura 4 - Normas de Sistema da Qualidade exigidas pelas montadoras Fonte: adaptado de Haro (2001)

Apesar dos vários pontos anteriormente apresentados que ressaltam a relevância das auditorias de processos, de acordo com pesquisa conduzida da por Haro (2001) entre as normas ISO 9001:2000, QS 9000, AVQS, EAQF e VDA 6, apenas esta última apresenta instruções específicas para a realização de auditorias em processos (VDA 6.3). A estrutura geral da norma VDA 6 é demonstrada pela figura 5 , onde destaque é dado à parte específica de auditoria de processos.

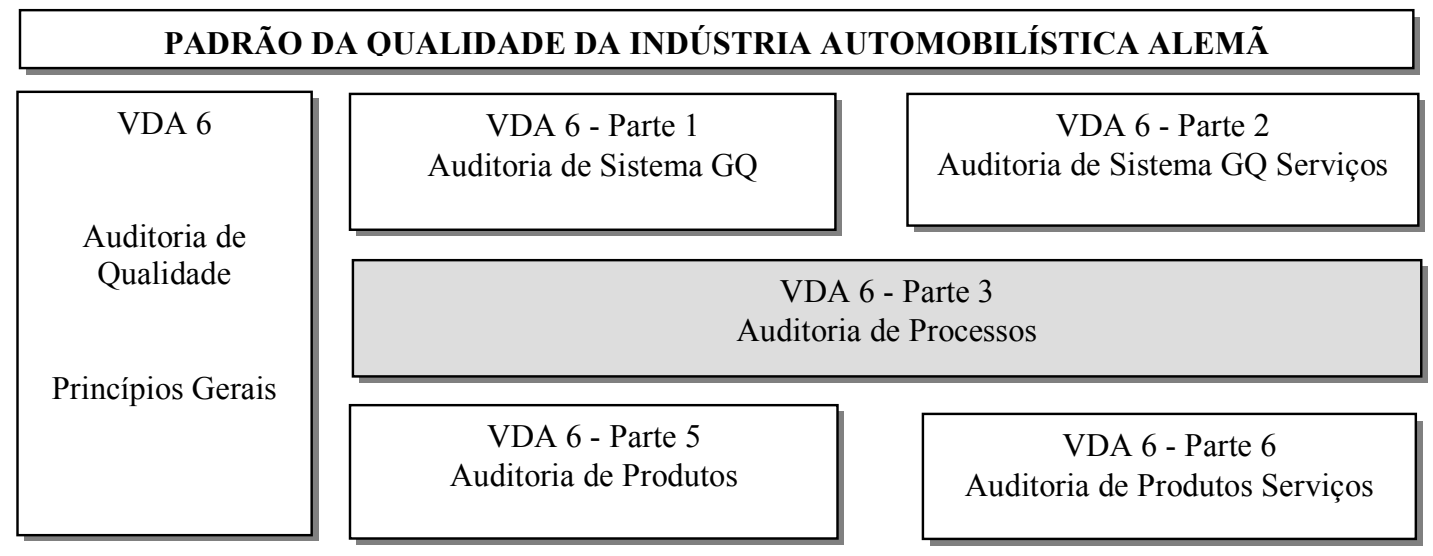

Figura 5 - Estrutura geral da norma VDA 6. Fonte: VDA $6.3(1998, \mathrm{p} .5)$

De acordo com definição específica da norma VDA 6.3 (1998, p.11), "as auditorias de processos servem para avaliar a eficácia da qualidade. Estas devem conduzir a processos mais eficientes e controlados, robustos a ponto de não estarem sujeitos a interferências". Para atingir este objetivo, a norma sugere:

a) Prevenção: reconhecimento, indicação e encaminhamento de medidas que evitem a primeira ocorrência de não-conformidades;

b) Correção: análise de deficiências conhecidas e medidas para eliminar e evitar recorrências;

c) Processo de Melhoria Contínua: ações tomadas a partir da auditoria de processo melhoram o processo, tornando-o paulatinamente mais eficiente e estável; 
d) Avaliação da qualidade: auxiliam nas conclusões sobre a eficácia de setores do sistema da qualidade.

Um dos pontos importantes ressaltados pela norma é relativo à experiência profissional dos auditores. A norma exige que um auditor de processos possua uma experiência mínima de dois anos no processo auditado.

A norma VDA 6.3 sugere uma estrutura específica para a auditoria de processo dividindo-a em duas partes, sendo que uma delas contempla especificamente os processos relacionados ao desenvolvimento de produtos e a segunda parte refere-se à análise dos processos produtivos propriamente ditos. A Figura 6 ilustra os elementos de cada uma destas partes.

\begin{tabular}{|ll|}
\hline \multicolumn{2}{|l|}{ Parte A: Processos de Desenvolvimento de Produtos } \\
\hline 1 & Planejamento do desenvolvimento dos produtos \\
\hline 2 & Concretização do desenvolvimento dos produtos \\
\hline 3 & Planejamento do desenvolvimento do processo \\
\hline 4 & Realização do desenvolvimento do processo \\
\hline Parte B: Produção em Série & \\
\hline 5 & Fornecedores / Matéria-prima \\
\hline 6 & Produção \\
\hline 6.1 & Pessoal / Qualificação \\
\hline 6.2 & Meios de Produção / Instalações \\
\hline 6.3 & Transporte / Manuseio de peças / Armazenamento / Embalagem \\
\hline 6.4 & Análises das falhas / Ações corretivas / Melhoria contínua \\
\hline 7 & Assistência ao cliente / satisfação do cliente \\
\hline
\end{tabular}

Figura 6 - Estrutura para a auditoria de processo sugerida pela VDA 6.3

Fonte: Elaborada a partir de VDA 6.3 (1998).

Em função do objetivo deste artigo, que se foca no estudo relativo ao elemento produção (elemento 6) e seus sub-elementos, detalha-se aqui apenas este elemento. A tabela 3 ilustra as questões sugeridas pela norma para a averiguação de cada sub-elemento, num total de 23 requisitos.

Segundo a norma VDA 6.3, a auditoria de processo tem um caráter avaliativo, ou seja, os processos são mensurados através de requisitos de análise qualitativos e recebem notas para cada requisito normativo estabelecido. O processo avaliado recebe uma nota para cada um dos 23 requisitos, sendo que essa nota varia de acordo com o grau de atendimento ao estabelecido pela norma VDA 6.3, conforme ilustrado pela tabela 4 . A composição da nota do processo auditado se constitui pela soma de pontos obtidos por cada requisito dividido pelo total de pontos possíveis, em uma escala que varia de $0 \%$ a $100 \%$.

Ao examinar os elementos abordados pela norma VDA 6.3 contidos na figura 7, pode-se notar, em especial pela apreciação das questões sugeridas, que a análise proposta por ela é bastante abrangente e profunda. Esta profundidade de análise aumenta ainda mais somando isso à experiência e ao conhecimento que devem possuir o auditor indicado para o processo.

Além disso, graças à divisão em sub-elementos, é possível a avaliação de quais são as áreas da empresa que necessitam de reforços, treinamentos ou mesmo investimentos. 


\begin{tabular}{|c|c|}
\hline Sub-elemento & Questões \\
\hline \multirow[t]{5}{*}{ 6.1 Pessoal/Qualificação } & $\begin{array}{l}\text { 6.1.1 Foram atribuídas ao pessoal responsabilidades e competências quanto à } \\
\text { supervisão da qualidade do produto e do processo? }\end{array}$ \\
\hline & $\begin{array}{l}\text { 6.1.2 Foram atribuídas ao pessoal, responsabilidades e competências relacionadas } \\
\text { com os equipamentos e ambiente da produção? }\end{array}$ \\
\hline & $\begin{array}{l}\text { 6.1.3 O pessoal encontra-se apto a assumir as tarefas e sua qualificação vem sendo } \\
\text { mantida? }\end{array}$ \\
\hline & $\begin{array}{l}\text { 6.1.4 Existe um plano de designação do pessoal com regulamentação das } \\
\text { substituições? }\end{array}$ \\
\hline & $\begin{array}{l}\text { 6.1.5 Os meios para aumentar a motivação do pessoal são empregados de modo } \\
\text { eficaz? }\end{array}$ \\
\hline \multirow{7}{*}{$\begin{array}{l}\text { 6.2 Meios de } \\
\text { Produção/Instalações e } \\
\text { Equipamentos }\end{array}$} & $\begin{array}{l}\text { 6.2.1 Os requisitos da qualidade específicos do produto são atendidos com os } \\
\text { equipamentos de produção/ferramental? }\end{array}$ \\
\hline & $\begin{array}{l}\text { 6.2.2 É possível supervisionar eficientemente os requisitos da qualidade durante a } \\
\text { produção em série com o auxílio dos equipamentos de medição e de testes } \\
\text { utilizados? }\end{array}$ \\
\hline & 6.2.3 Os locais de trabalho e de testes atendem às necessidades? \\
\hline & $\begin{array}{l}\text { 6.2.4 Os dados importantes na documentação dos equipamentos de produção e de } \\
\text { inspeção são especificados na íntegra e estes são cumpridos? }\end{array}$ \\
\hline & $\begin{array}{l}\text { 6.2.5 Encontram-se disponíveis os materiais auxiliares necessários para trabalhos de } \\
\text { ajustes e regulagem? }\end{array}$ \\
\hline & $\begin{array}{l}\text { 6.2.6 É realizada uma liberação dos processos de produção e são registrados os } \\
\text { dados de regulagem e ajustes bem como os valores divergentes? }\end{array}$ \\
\hline & $\begin{array}{l}\text { 6.2.7 As ações corretivas necessárias são tomadas dentro do prazo estipulado, } \\
\text { testando-se a eficácia de tais ações? }\end{array}$ \\
\hline \multirow{5}{*}{$\begin{array}{l}\text { 6.3 Transporte/Manuseio de } \\
\text { Peças/Armazenamento/ } \\
\text { Embalagem }\end{array}$} & $\begin{array}{l}\text { 6.3.1 As quantidades/lotes de produção estão de acordo com a necessidade e estes } \\
\text { são passados sistematicamente á etapa de trabalho posterior? }\end{array}$ \\
\hline & $\begin{array}{l}\text { 6.3.2 Os produtos/componentes são armazenados de acordo com a sua utilidade e } \\
\text { os meios de transporte/dispositivos de embalagem estão de acordo com as } \\
\text { características especiais dos produtos/componentes? }\end{array}$ \\
\hline & $\begin{array}{l}\text { 6.3.3 São separadas de modo estrito as peças rejeitadas, para retrabalho, bem como } \\
\text { os resíduos produzidos dentro da empresa? }\end{array}$ \\
\hline & $\begin{array}{l}\text { 6.3.4 O fluxo de material e de componentes está seguro contra misturas, trocas por } \\
\text { engano, estando garantida sua rastreabilidade? }\end{array}$ \\
\hline & $\begin{array}{l}\text { 6.3.5 O ferramental, os dispositivos, equipamentos e os materiais de inspeção são } \\
\text { armazenados de modo apropriado? }\end{array}$ \\
\hline \multirow{6}{*}{$\begin{array}{l}\text { 6.4 Análise das } \\
\text { Falhas/Correções/Melhoria } \\
\text { Contínua }\end{array}$} & $\begin{array}{l}\text { 6.4.1 Os dados da qualidade e do processo são registrados de forma abrangente para } \\
\text { que estes possam ser avaliados? }\end{array}$ \\
\hline & $\begin{array}{l}\text { 6.4.2 Os dados da qualidade e do processo passam por uma avaliação estatística, } \\
\text { resultando desta avaliação programas de melhoria? }\end{array}$ \\
\hline & $\begin{array}{l}\text { 6.4.3 É feita uma análise das causas no caso de divergência relativas aos requisitos } \\
\text { do produto e do processo e é realizado um exame das ações corretivas quanto à sua } \\
\text { eficácia? }\end{array}$ \\
\hline & 6.4.4 Os processos e produtos são submetidos regularmente a uma auditoria? \\
\hline & 6.4.5 O produto e o processo são objeto de melhoria contínua? \\
\hline & $\begin{array}{l}\text { 6.4.6 São estipuladas metas tanto para o produto como para o processo, existindo } \\
\text { um controle que verifica se estas são atingidas? }\end{array}$ \\
\hline
\end{tabular}

Figura 7 - Sub-elementos que compõem o elemento 6 - Produção

Fonte: Elaborada a partir de VDA 6.3 (1998)

Este referencial teórico serviu de base para a condução do estudo de caso deste trabalho, permitindo ampliar a compreensão da prática da auditoria de processos nas empresas e, juntamente com os conceitos estudados na revisão teórica, construir um conjunto de considerações que podem ser bastante úteis para a condução de auditorias de processos nas organizações. Feitas as considerações auditoria de processo, sua relação com a melhoria contínua e sobre a norma VDA 6.3, o próximo tópico introduz o estudo de caso aqui pretendido, através da descrição da metodologia adotada para a condução desta pesquisa. 


\begin{tabular}{ll}
\hline Número de pontos & Avaliação do cumprimento de exigências isoladas \\
\hline 0 & Não atendimento ao requisito da norma \\
\hline 4 & Atendimento parcial ao requisito, causando riscos à performance do produto \\
\hline 6 & $\begin{array}{l}\text { Atendimento parcial ao requisito, podendo gerar falhas internas na manufatura e } \\
\text { pequenas falhas no produto }\end{array}$ \\
\hline 8 & $\begin{array}{l}\text { Atendimento parcial ao requisito, podendo gerar pequenas falhas no processo de } \\
\text { manufatura, não gerando falhas no produto }\end{array}$ \\
\hline 10 & Atendimento pleno ao requisito. Processo está isento de falhas \\
\hline
\end{tabular}

Tabela 1 - Pontuação do processo

Fonte: adaptada de VDA 6.3 (1998)

\section{Metodologia de pesquisa utilizada neste trabalho}

Com o objetivo de apresentar a auditoria de processos como suporte à melhoria contínua, foi realizada uma investigação na empresa Volkswagen do Brasil LTDA., na planta de São José dos Pinhais (BUC Business Unit Curitiba), responsável pela fabricação dos automóveis modelos Fox, Audi e Golf. A escolha desta empresa se deu pelo fato dela realizar já há alguns anos auditorias periódicas em seus processos de acordo com os preceitos da norma VDA 6.3. Por isso, a empresa já possui dados suficientes que podem ser utilizados para demonstrar a evolução de suas notas de auditoria de processo e também possibilitar o acompanhamento da efetividade das ações preventivas e corretivas realizadas.

Devido ao elevado número de processos envolvidos na produção de automóveis e à sua complexidade, se fez necessária a escolha de um processo específico para a pretendida análise. Esta investigação focou-se, então, no processo denominado Montagem de Partes Móveis da área de Armação de Carrocerias do modelo Fox, onde foram analisados os resultados das auditorias realizadas neste processo durante o período compreendido entre janeiro de 2004 a agosto de 2005 . O processo de Montagem de Partes Móveis é um dos mais críticos na armação, pois exige a habilidade do operador no ajuste das peças no veículo e se constitui em um processo dependente da estabilidade dos processos anteriores para garantir o correto faceamento e folgas das peças dentro das especificações.

Essa análise procurou verificar as não-conformidades identificadas quanto à sua relevância (nota da não-conformidade) e aplicação (área de melhoria).

Outro recorte que se fez necessário para a condução desta pesquisa se relaciona aos itens da norma contemplados. Conforme já mencionado no tópico 3, pela abrangência dos elementos abordados pela norma VDA 6.3, foram analisados apenas dados relativos aos itens abarcados pelo elemento 6 (Produção).

Levando em conta os objetivos pretendidos com a presente investigação, esta pesquisa foi enquadrada quanto à abordagem, ao método de pesquisa e quanto ao instrumento utilizado para a coleta de dados. Com relação à abordagem, de acordo com o critério adotado por Westbrook (1995), entre a abordagem qualitativa e a quantitativa, concluiu-se que a abordagem qualitativa seria a mais adequada para $o$ desenvolvimento desta pesquisa já que haveria a necessidade da presença do pesquisador, contaria com variáveis de difícil mensuração, além de enfatizar o processo dos acontecimentos, ou seja, a evolução dos fatos ao longo do tempo (BRYMAN, 1989).

Quanto ao método de pesquisa, Nakano e Fleury (1996) consideram cinco tipos: experimental, survey, pesquisa participante, pesquisa ação e estudo de caso. Com base nas características desta pesquisa foi escolhido o método estudo de caso já que o propósito deste estudo centra-se em proporcionar exemplificação do panorama geral da auditoria de processos em uma empresa e não a generalização dos dados para quaisquer outras situações. 
Por fim, para a coleta das informações foram utilizadas três técnicas distintas: análise documental, entrevistas diretivas seguindo um roteiro semi-estruturado e observação visual in loco. Para a análise documental, foram utilizados dados históricos e detalhados da empresa sobre os resultados das auditorias durante o período investigado. As entrevistas foram realizadas com os gerentes da área de Armação de Carrocerias e da qualidade e também com o auditor do processo estudado. O roteiro das entrevistas continha questões pré-formuladas em que os entrevistados tiveram liberdade para fazer inserções consideradas relevantes. As questões tinham como objetivo levantar informações sobre:

a) O processo de auditoria adotado pela empresa;

b) Resultados obtidos através das auditorias de processo;

c) Relevância da auditoria de processo para a empresa.

A observação visual in loco teve como objetivo a melhor compreensão tanto do processo estudado quanto da sistemática de execução da auditoria de processo.

\section{Descrição e discussão do caso estudado}

Visando proporcionar maior compreensão do processo focado neste estudo de caso, este tópico realiza a descrição e o posicionamento deste processo dentre os demais processos produtivos da empresa. Em seguida, encontram-se a apresentação e a análise dos dados coletados.

\subsection{Descrição e posicionamento do processo estudado}

A empresa estudada possui quatro áreas principais, sendo elas denominadas:

a) Estamparia: compreende um conjunto de processos que objetivam a fabricação das partes que constituem a carroceria do automóvel, como laterais, capôs e portas;

b) Armação: aqui as partes constituintes da carroceria produzidas na estamparia são unidas, formando a carroceria do automóvel;

c) Pintura: conjunto de processos destinados à proteção contra corrosão e aspecto visual da carroceria previamente soldada para ser montada;

d) Linha de montagem: processos destinados à montagem do automóvel a partir da carroceria, agregando a ela os componentes do automóvel.

A área da Armação, a qual é o foco desse estudo de caso, possui dezessete processos destinados à montagem das carrocerias dos três modelos fabricados pela unidade (Golf, Audi e Fox). Sete destes processos referem-se especificamente à fabricação do Volkswagen modelo Fox. A figura 8 mostra o fluxo simplificado destes sete processos. As setas cheias indicam o fluxo da carroceria e as setas tracejadas indicam o fluxo das partes constituintes (laterais, portas, paralamas, capô e tampa traseira).

Estes sete processos representam todas as etapas produtivas da área de Armação de Carrocerias do modelo Fox, onde são aplicados os elementos de análise da auditoria de processo. Além das áreas produtivas, existem áreas de apoio, como a Logística, Controle Dimensional (sala de medidas), Manutenção, Engenharia de Manufatura, Engenharia Industrial, Qualidade Assegurada e Segurança do Trabalho. Estas áreas de apoio também são avaliadas por auditorias de processo, mas apenas como interface da área produtiva, porque a Norma VDA 6.3, na parte 6 (acompanhamento da produção em série), foca apenas o processo de produção direto, não havendo auditorias exclusivas em áreas de apoio. 


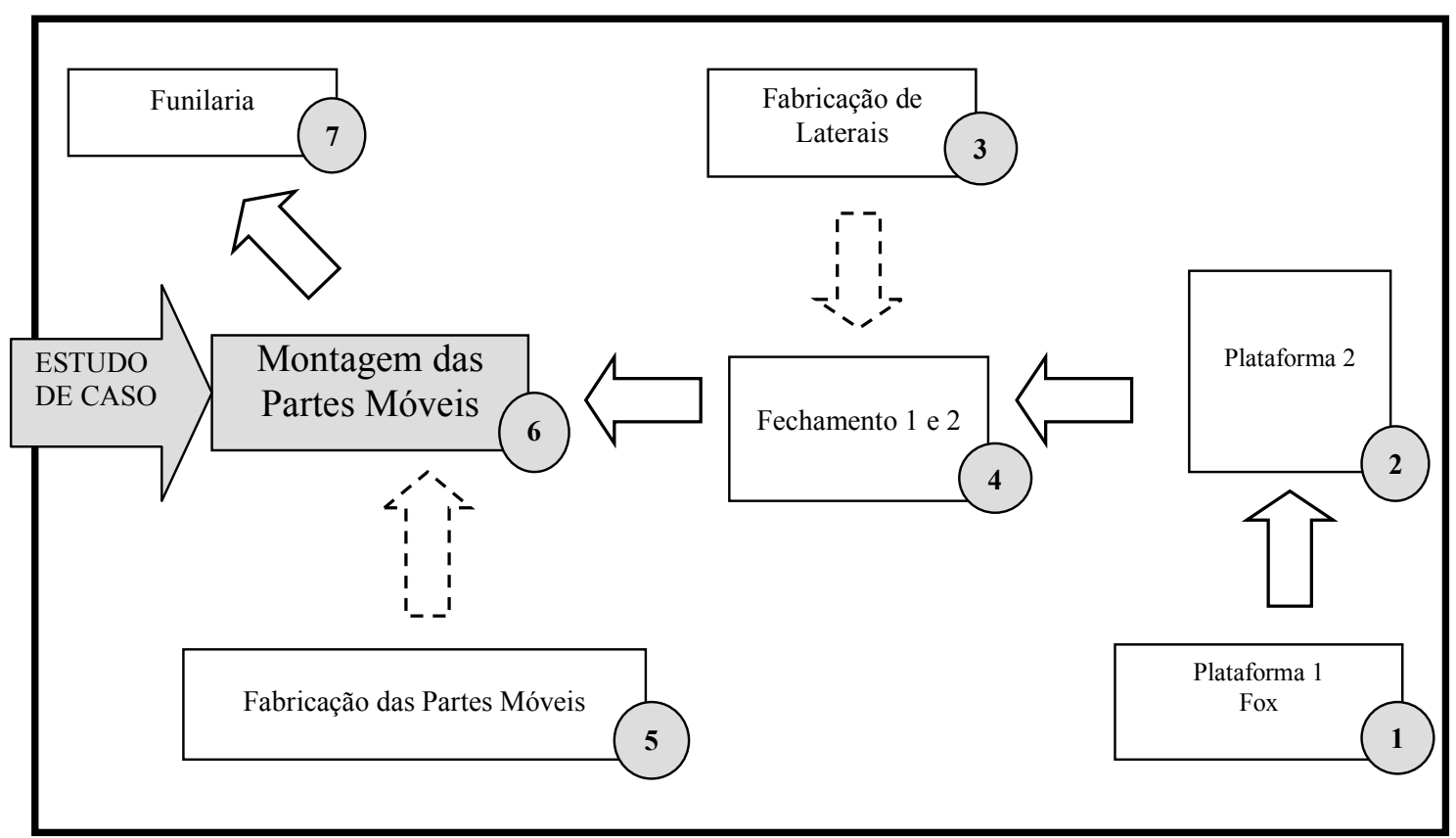

Figura 8 - Fluxo simplificado dos processos da Armação de Carrocerias do modelo Fox

O objetivo principal dessa norma é garantir o processo produtivo, sendo assim, as áreas de apoio somente irão ser auditadas quando estiverem interferindo na execução de tarefas da área de manufatura. Uma descrição breve de cada um desses sete processos pode ser visualizada na tabela 2 , onde destaque é dado ao processo 6, objeto desta análise.

Tabela 2 - Descrição dos processos de armação do modelo Fox

\begin{tabular}{lll}
\hline Processo & Descrição \\
\hline 1 & Plataforma 1 & $\begin{array}{l}\text { Solda das chapas que irá formar as longarinas, assoalho dos } \\
\text { passageiros e região do porta-malas. }\end{array}$ \\
\hline 2 & Plataforma 2 & Solda das caixas de roda, região do cockpit e painel traseiro. \\
\hline 3 & Laterais & Solda da chapa externa, chapa interna e reforços das colunas. \\
\hline & \multirow{2}{*}{ Fechamento 1 e 2 } & $\begin{array}{l}\text { No Fechamento 1 são unidas as laterais e o teto à plataforma. } \\
\text { Essa união ocorre através de solda laser, em seguida são } \\
\text { aplicadas soldas para reforçar essa união, na área do }\end{array}$ \\
& Fechamento 2. \\
\hline 5 & Fabricação de Partes Móveis & $\begin{array}{l}\text { Soldagem das peças estampadas que irão formar as portas, } \\
\text { tampa traseira, tampa dianteira (capô) e pára-lamas. Estas } \\
\text { peças são fabricadas e disponibilizadas na linha de Montagem } \\
\text { de Partes Móveis. }\end{array}$ \\
\hline \multirow{2}{*}{ Montagem de Partes Móveis } & $\begin{array}{l}\text { A carroceria, já com teto e laterais, se direciona para a } \\
\text { área de Montagem de Partes Móveis, onde são feitas as } \\
\text { fixaçóes através de uniões aparafusadas. Aqui também é } \\
\text { realizado o ajuste da carroceria. }\end{array}$ \\
\hline & Funilaria (acabamento) & $\begin{array}{l}\text { Antes de enviar a carroceria para a pintura, ela passa por um } \\
\text { processo de verificação e ajustes, que incluem pequenos } \\
\text { reparos na superfície (lixamento e polimento) e reparos nas } \\
\text { soldas. }\end{array}$ \\
\hline
\end{tabular}




\subsection{Descrição e análise dos dados}

A descrição e a avaliação dos dados coletados obedecem a uma estrutura que parte de uma abordagem abrangente, em que são demonstrados os resultados das auditorias realizadas neste processo (Montagem de Partes Móveis - modelo Fox) durante o período estipulado.

A seguir, as não-conformidades identificadas foram agrupadas nos sub-elementos da VDA 6.3. Por fim, foram selecionadas para investigação sete não-conformidades, que segundo os entrevistados, tiveram maior impacto no incremento da eficiência geral do processo.

\subsubsection{Avaliação geral}

Durante o período do estudo, foram realizadas quatro auditorias em intervalos de seis meses no processo Montagem de Partes Móveis do modelo Fox. Através da observação das notas obtidas na avaliação do elemento 6 da norma VDA 6.3, pode-se notar um expressivo aumento na nota atribuída ao processo analisado (Figura 9).

Em números absolutos, nas duas auditorias realizadas em 2004 foram identificadas trinta e uma nãoconformidades, sendo que em 2005 este número caiu para dezessete. Assim, com a efetivação das ações de melhoria no processo auditado, nota-se uma evidente melhoria nos resultados das auditorias posteriores, sendo que a diminuição das não-conformidades identificadas está de acordo com a evolução da nota atribuída ao processo.

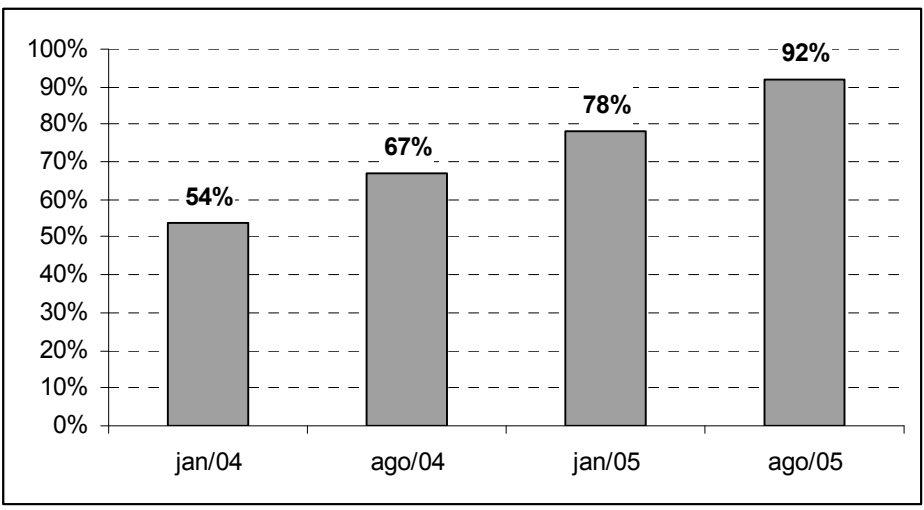

Figura 9 - Evolução da Nota da Montagem de Partes Móveis - Fox

\subsubsection{Avaliação de acordo com sub-elementos da norma VDA 6.3}

As auditorias de processos conduzidas de acordo com a norma VDA 6.3 permitem a classificação das não-conformidades de acordo com os sub-elementos, possibilitando a avaliação de quais grupos de fatores da empresa que necessitam de reforços.

A análise da evolução das notas parciais de acordo com os sub-elementos permite ainda a verificação da efetividade das ações tomadas entre as auditorias. Para exemplificar, apresenta-se a figura 6 que ilustra a distribuição das não-conformidades encontradas nas auditorias de processo realizadas durante os anos de 2004 e de 2005 , de acordo com os itens da norma.

É possível observar, pela análise da figura 6, que houve uma evolução significativa do processo auditado, principalmente em relação ao aspecto de pessoal/qualificação (elemento 6.1), que diminuiu de nove para apenas duas não-conformidades no período de um ano e meio, refletindo uma mudança comportamental positiva e maior organização dos funcionários. Destaca-se também a evolução referente ao elemento 6.2 (meios de produção/instalações), como conseqüência de melhorias nas instalações, máquinas, equipamentos e meios auxiliares (equipamentos de testes, por exemplo). 


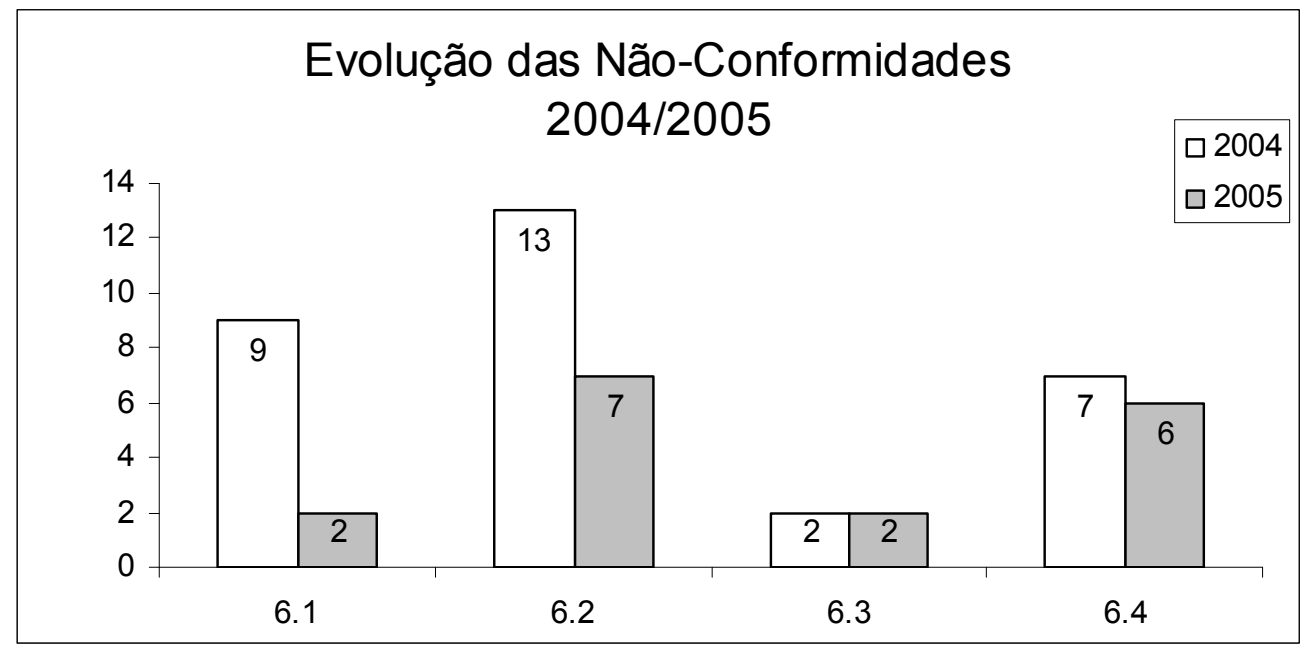

Figura 10 - Distribuição das observações por item da norma - anos de 2004 e 2005

\subsubsection{Avaliação detalhada do processo auditado}

A tabela 3 apresenta, para as sete não-conformidades selecionas, a descrição da não-conformidade, as suas evidências, os itens da norma VDA 6.3 a que se referem e as notas atribuídas.

Tabela 3 - Não-conformidades encontradas na de auditoria do processo

\begin{tabular}{|c|c|c|c|}
\hline Não-conformidade & Evidência & $\begin{array}{c}\text { Item VDA } \\
6.3 \\
\end{array}$ & Nota \\
\hline $\begin{array}{l}\text { 1. Ajuste do pára-lama sem } \\
\text { utilização de calibrador. }\end{array}$ & $\begin{array}{l}\text { Operador realiza ajuste do pára-lama apenas com o } \\
\text { parâmetro visual, não fazendo uso do calibrador de } \\
\text { ajuste. }\end{array}$ & 6.1 .1 & 6 \\
\hline 2. Operador sem qualificação. & $\begin{array}{l}\text { Dois dos operadores não foram re-qualificados no } \\
\text { ano anterior para a realização de solda MIG/MAG. }\end{array}$ & 6.1 .3 & 4 \\
\hline $\begin{array}{l}\text { 3. Utilização de produto não } \\
\text { liberado. }\end{array}$ & $\begin{array}{l}\text { Solvente utilizado no espatulamento da cola do } \\
\text { pára-lama não está sendo liberado pela segurança } \\
\text { do trabalho. }\end{array}$ & 6.2 .3 & 6 \\
\hline $\begin{array}{l}\text { 4. Furo do pára-lama realizado de } \\
\text { maneira irregular. }\end{array}$ & $\begin{array}{l}\text { Operador utiliza-se de um martelo e de uma chave } \\
\text { tipo Philips para abrir o furo de fixação do pára- } \\
\text { lama na coluna, não havendo qualquer garantia de } \\
\text { uniformidade na furação realizada. }\end{array}$ & 6.2 .4 & 4 \\
\hline $\begin{array}{l}\text { 5. Não realização de inspeção nas } \\
\text { folgas e faceamentos das portas } \\
\text { do automóvel. }\end{array}$ & $\begin{array}{l}\text { Segundo instruções, deve ser realizada a } \\
\text { verificação de folgas e faceamento das portas do } \\
\text { automóvel, a cada } 5 \text { carros. Durante a auditoria, } \\
\text { passaram } 11 \text { carros e não foi realizado tal teste. }\end{array}$ & 6.4 .3 & 6 \\
\hline $\begin{array}{l}\text { 6. Manutenção em parafusadeiras } \\
\text { não executada. }\end{array}$ & $\begin{array}{l}\text { Parafusadeiras eletrônicas sendo utilizadas com } \\
\text { fita adesiva para a fixação de suas partes. }\end{array}$ & 6.2 .1 & 8 \\
\hline $\begin{array}{l}\text { 7. Procedimento de avaliação } \\
\text { inexistente. }\end{array}$ & $\begin{array}{l}\text { Não está sendo realizada a liberação da solda } \\
\text { MIG/MAG da sapata da longarina. }\end{array}$ & 6.2 .6 & 4 \\
\hline
\end{tabular}

A não-conformidade 1 refere-se ao elemento 6.1, na qual um operador realizava uma tarefa de ajuste do paralama sem o auxílio do calibrador de folga. O desenho do produto especifica uma tolerância de $0,5 \mathrm{~mm}$ para a folga do paralama em relação ao capô do veículo. $O$ auditor, através de sua experiência, concluiu que não seria possível garantir tal especificação apenas utilizando elementos sensoriais (tato ou visão).

Como ação corretiva, a área de Engenharia de Manufatura desenvolveu calibradores de folga (como meio de inspeção) e a área de Qualidade Assegurada elaborou "cartões" de folga (informações sobre 
as especificações), além de ministrar o treinamento aos operadores. A área de Manutenção ficou encarregada de controlar o desgaste dos calibradores e fazer sua substituição quando necessária.

A não-conformidade 2 refere-se à não re-qualificação dos operadores que realizam solda MIG/MAG na sapata da longarina do veículo. A re-qualificação dos soldadores deveria ser anual, conforme prevê o procedimento da área de Recursos Humanos (RH). Como ação corretiva, a área de manutenção (responsável por ministrar o treinamento) elaborou uma lista dos operadores de solda MIG/MAG, a qual foi adotada como referência pela área de RH para garantir a realização das re-qualificações.

A não-conformidade 3 é relativa à segurança do funcionário ao manusear um determinado produto químico na área de Manufatura. O produto em questão (solvente) é altamente volátil e poderia ocasionar náuseas ao operador. A área de Segurança do Trabalho analisou a questão e institui o uso do EPI adequado (máscara e luvas).

A não-conformidade 4 está ligada a uma falha da Engenharia de Manufatura, que não previu a atividade de furação do para-lama para fixação de um parafuso. Como ação, foi desenvolvido um punção adequado para realizar a tarefa.

Em relação à não-conformidade 5, o auditor percebeu que um procedimento da Qualidade Assegurada estabelecia que, a cada cinco carrocerias, uma deveria ter suas folgas verificadas por um inspetor no final da linha de Montagem de Partes Móveis, freqüência que não estava sendo obedecida. Como ação, a tarefa de verificação das folgas realizadas passou para a área de Auditoria de Carrocerias (auditoria de produto), a qual manteve a freqüência estabelecida.

A área de Manutenção foi responsável pela não-conformidade 6, que tomou a ação de criar um quadro de prioridades de manutenção na área, onde os colaboradores passaram a anotar todos os itens que necessitavam de reparos para serem realizados nos fins de semana.

Por fim, a não-conformidade 7 refere-se ao processo de verificação de solda. Por uma questão técnica, a freqüência de verificação de solda não estava sendo cumprida. Como ação corretiva, a área de manufatura liberou a compra de mais dois aparelhos de teste, podendo, então, cumprir a freqüência determinada.

\section{Conclusões}

Além de mostrar como a auditoria de processo auxilia na melhoria contínua, esse artigo ilustrou a identificação das particularidades da auditoria de processo perante as outras auditorias da qualidade. Quando comparada à auditoria de sistema, destaca-se o papel do auditor como uma figura envolvida com o processo a ser auditado, o que em uma auditoria de sistema normalmente é considerado negativo, pois se acredita que o auditor poderia ser tendencioso em sua análise. Em comparação à auditoria de produto, a singularidade da auditoria de processo fica a cargo de seu aspecto preventivo em contraponto ao aspecto corretivo da auditoria de produto.

Porém, como dito, a auditoria de processo vem sendo relegada ao segundo plano, apesar de sua eficiência no auxílio à melhoria contínua. É importante salientar que, não obstante as outras normas de gestão da qualidade que regem a indústria automobilística (ISO 9001:2000, QS 9000, AVQS e EAQF) não exigirem a execução de auditorias de processo, o IATF (International Automotive Task Force ${ }^{2}$ )

\footnotetext{
${ }^{2}$ Em 1995, pela constatação da inexistência de um reconhecimento mútuo entre os vários referenciais existentes, o IATF (International Automotive Task Force), a partir da norma ISO 9001:1994, iniciou o desenvolvimento de um referencial comum, incluindo os requisitos dos vários fabricantes e que fosse reconhecido por todos. No ano de 1999 surge, então, a Especificação Técnica ISO/TS 16949, particular para a indústria automobilística. Atualmente, a norma ISO/TS 16949:2002, se constitui em um referencial comum e único a todos os membros do IATF, devendo ser adotada por todas as empresas participantes da cadeia de fornecimento da indústria automobilística.
} 
está recomendando às montadoras, bem como aos seus fornecedores, a transição para a norma de gestão da qualidade ISO/TS 16949:2002. Esta transição acarretará na obrigatoriedade da realização de auditoria de processo de forma periódica, o que deverá proporcionar-lhe maior destaque.

Neste estudo, os dados coletados em campo foram divididos em 3 categorias: avaliação geral do processo de Montagem de Partes Móveis, avaliação do processo conforme sub-elementos da norma VDA 6.3 e avaliação detalhada.

A nota de avaliação geral do processo estudado apresentou um aumento de $38 \%$ durante o período de pesquisa, com uma redução no número de não-conformidades de trinta e uma para dezessete. A diminuição gradativa do número de não-conformidades observadas ao longo das auditorias permite concluir que as ações tomadas atuaram na causa dos problemas.

Em relação à avaliação por sub-elementos da norma, foi possível demonstrar que a evolução da nota geral foi devida, principalmente, a melhorias nos sub-elementos 6.1 (pessoal/qualificação) e 6.2 (meios de produção/instalações), evidenciando a capacidade deste tipo de auditoria em identificar, por áreas, a efetividade das ações tomadas.

Por meio da análise detalhada, pode-se dizer que as ações realizadas pela empresa a partir das sete não-conformidades identificadas pela auditoria de processo demonstram:

- maior envolvimento da mão-de-obra direta e do pessoal de apoio (engenharia, manutenção, qualidade e logística) com o processo. A ação de melhoria a partir da não-conformidade 1, por exemplo, teve o envolvimento dos operadores e das áreas de Engenharia de Manufatura, Qualidade Assegurada e Manutenção;

- melhorias nos meios de produção e instalações do processo de manufatura, conforme pode ser verificado pela ação tomada para a não-conformidade 7, por exemplo.

Desta maneira, pode-se concluir que a auditoria de processo é uma ferramenta que auxilia na melhoria contínua, uma vez que:

- É capaz de identificar necessidades de melhoria nos processos;

- Mostra-se eficiente na diminuição das não-conformidades no processo;

- Envolve os participantes diretos da operação na tomada de ações de melhoria;

- Conduz a busca de melhorias na causa raiz dos problemas.

Ainda conforme o estudo de caso apresentado, pode-se observar que as ações de melhoria propostas só podem ser implementadas pelos envolvidos no processo em questão. É importante destacar, entretanto, o envolvimento do auditor de processo na solução dos problemas identificados durante a auditoria. Sua participação ativa na elaboração das soluções possibilita uma melhor avaliação das ações implementadas. Merece destaque, também, a capacidade do auditor de processos de identificar nãoconformidades que possivelmente não seriam observadas pelos demais auditores da qualidade. As não-conformidades 1, 3, 4 e 6, por exemplo, somente puderam ser identificadas devido aos conhecimentos detalhados do auditor sobre o processo avaliado.

Além do setor automobilístico, outros setores industriais poderiam se beneficiar da aplicação da auditoria de processo, pois seu caráter é abrangente e genérico, não havendo qualquer restrição para sua utilização em qualquer outro tipo de indústria. Alguns setores já estão fazendo uso dessa ferramenta da qualidade, como é o caso do setor de eletrodomésticos (fabricante de produtos da linha branca).

\section{Referências}

BAFNA, S. The process audit: often ignored but never insignificant. Quality Progress, p. 37-40, Dec. 1997. 
BRYMAN, A. Research methods and organization studies. London: Routledge, 1989.

CAMPOS, V. F. TQC: Controle da Qualidade Total. 6.ed. Rio de Janeiro: Fundação Christiano Ottoni, 1992.

COLE, R. E. From continuous improvement to continuous inovation. Quality Management Journal Berkeley University, California, Oct. 2001.

FERNANDES, J. M. R. Proposta de um sistema de gestão da qualidade integrado baseado no FMEA. Dissertação (Mestrado) - Departamento de Engenharia de Produção - Pontifícia Universidade Católica do Paraná. Curitiba, 2005.

HAMEL, G.; PRAHALAD, C. K. Competindo para o futuro. Rio de Janeiro: Campus, 1995.

HARO, D. G. Sistemas da qualidade na indústria automobilística: uma proposta de auto-avaliação unificada. Dissertação (Mestrado)- Departamento de Engenharia de Produção - Universidade Federal do Rio Grande do Sul, UFRGS, 2001.

IMAI, M. Gemba kaizen: a commonsense, low-cost approach to management. New York: McGrawHill, 1997.

MENDA, R. The role of manufacturing audit in crafting the production system. International Journal of Operations \& Production Management, vol. 24, p. 929, 2004.

MILLS, A. C A auditoria da qualidade: uma ferramenta para avaliação constante e sistemática da manutenção da qualidade. 5.ed. São Paulo: Makron Books, 1994.

NAKANO, D. N.; FLEURY, A. Métodos de pesquisa em Engenharia de Produção. In: XVI Encontro Nacional de Engenharia de Produção, Piracicaba, 1996. Anais...

RITZMAN, L. P.; KRAJEWSKI, L. J. Administração da produção e operações. São Paulo: Prentice Hall, 2004.

SKINNER, W. Manufacturing in the Corporate Strategy. New York: Wiley, 1978.

SLACK, N.; CHAMBERS, S.; JOHNSTON, R. Administração da Produção. São Paulo: Atlas, 2002.

VDA 6.3 (Verband Der Automobilindustrie). Gerenciamento do Sistema da Qualidade na Indústria Automobilística: Auditoria do Processo (Parte 3). São Paulo: IQA - Instituto da Qualidade Automotiva, 1998.

WESTBROOK, R. Action research: a new paradigm for research in production and operations management. International Journal of Production and Operations Management, v.15, n.12, p. 6-20, 1995.

WYNNE, D.; MANNERS, P. Process audit: for project improvement, not punishment. Quality Audit Conference Transactions, Atlanta, v.10, n.0, p. 63-73, Feb. 2001.

WOMACK, J. P.; JONES, D. T.; ROOS, D. A máquina que mudou o mundo. Rio de Janeiro: Campus, 1992. 